THE EFFECTS OF IONIZING RADIATION ON AQUATIC ORGANISHS

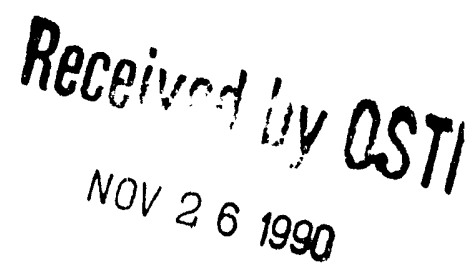

W. L. Templeton

B. G. Baylock

September 19990

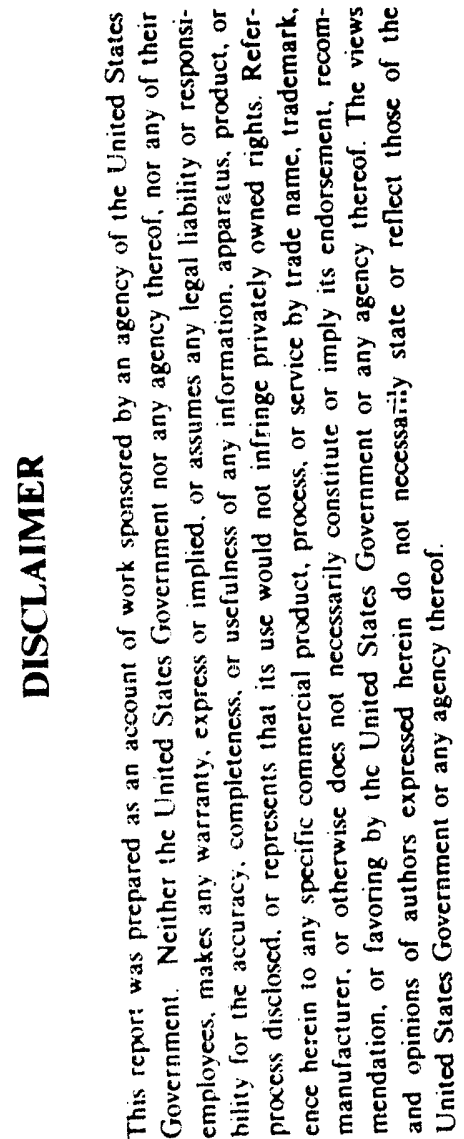

Presented at the

Biological Effects of

Chernotyl Accirant

USSR

September 10-18, 1990

Work Supported by

the Department of Energy

under Contract DE-ACO6-76RLO 1830

Pacific Northwest Laboratory

Richland, Washington 9 y 352 


\title{
THE EFFECTS OF IONIZING RADIATION ON AQUATIC ORGANISMS
}

\author{
William L. Templeton' ${ }^{1}$ and B. Gordon Blaylock 2 \\ 1 Pacific Northwest Laboratory, Richland, WA, USA. \\ 2 Oak Ridge National Laboratory, Oak Ridge, TN, USA.
}

Scientific Committee \#64-6 of the Nacional Council on Radiation Protection (NCR:; of the United States has recently completed a review of the literature on the effects of ionizing radiation on aquatic organisms (NCRP 1990). In this report, the NCRP provides guidance for a dose rate below which deleterious effects to aquatic organisms are acceptably low; reviews a series of simple dosimetric models that can be applied to demonstrate compliance with such a dose rate; provides examples of the application of the models to contaminated aquatic environments; and evaluates the validity of the statement of the International Commission on Radiation Protection (ICRP 1977) that "if man is adequately protected inen other living things are also likely to be sufficiently protected."

The discharge of the low-level radioactive effluents into the aquatic environment has resulted in chronic, low dose rate exposure to aquatic organisms. The fate of individual organisms is, generally, not the major concern; the major concern is the maintenance of endemic populations and their response to the exposure. Experimental studies to date have shown that fertility and fecundity (gametogenesis) of the organisms and the period of embryonic development are probably the most sensitive components of the radiation response, and it is precisely these attributes that are of importance in determining the fate of the population.

It must be recognized that increased radiation exposure is but one of the many stresses imposed upon aquatic populations by human activities. However, determination of the interactions of radiation, whether they be antagonistic, additive, or synergistic, with other environmental contaminants or stressors is extremely difficult to assess under conditions of chronic exposure.

From the information reviewed, in this report, it appears that a chronic dose rate of no greater than $0.4 \mathrm{mGy} \mathrm{h}^{-1}$ to the maximally exposed individual in a population of aquatic organisms would ensure protection for the populatjon. If modelling and/or dosimetric measurements indicate a level of $0.1 \mathrm{mGy} \mathrm{h}^{-1}$, then a more detailed evaluation of the potential ecological consequences to the endemic population should be conducted.

A review of the three existing dosimetry models and associated codes indicates that they are all appropriate for estimating radiation dose rates to aquatic organisms. The CRITh model (Soldat et al. 1974) would appear to be the most useful approach to adopt in any preoperational assessment phase of planned waste management activities that will result in radionuclides being released to

Footnote: The authors of this NCRP report (NCRP 1990) are the co-chairpersons of NACRP Scientific Committee 64-6. Other members of the task group are D. W. Engei, A. D. Kligerman, J. R. Trabalka, D. S. Woodhead and A. S. Seymour. 
the aquatic environment. The Point Source Dose Distribution (PSDD) functions (IAEA 1976; IAEA 1979) require considerable detail on radionuclide distributions to realize their full potential and would be most appropriately applied in contaminated environments where data have been collected specifically for environmental dosimetry. These functions are particularly useful for application to small organisms (e.g., developing embryos) or where it is necessary to estimate the dose rate to a radiosensitive tissue, such as the gonads, from a nonuniform radionuclide distribution. The BIORAD model (Trubey and Kaye 1973) is less useful than the other two models since the potentialiy significant exposure of an organism to contaminated sediments is not considered.

These models were applied to three contaminated aquatic environments in North America for which data were available to estimate the radiation doses to aquatic biota. The majority of the estimated whole body doses received by aquatic organisms at all three sites examined was more than two orders of magritude below the proposed standard of $0.4 \mathrm{mGy} h^{-1}$. However, at two of the sites there are a few maximum values that approach that value and exceed the dose of $0.1 \mathrm{mGy} h^{-1}$, at which a more detailed evaluation is proposed. These higher doses occur in manmade bodies of water associated with waste management activities and have no direct connection with bodies of natural water at these sites. For example, the internal dose values from $90 \mathrm{sr}$ in turtles exposed in seepage basins at the U.S. Department of Energy (DOE) Savannah River Plant exceeded the proposed evaluation dose of $0.1 \mathrm{mG} \mathrm{h}^{-1}$. However, these seepage basins have been fenced to preclude the ingress or egress of turtles, and a permanent closure plan for these basins is being developed. At Gable Mountain Pond at the DOE Hanford Plant, insects, molluscs, and small fish externally exposed to ${ }^{137} \mathrm{Cs}$ from contaminated sediments also exceeded the proposed evaluation dose. Again, remediation and restoration action has been taken; the pond has been drained and the sediments covered with clean soil.

The report also evaluated the validity of the statement by the ICRP (1977) that "if mon is adequately protected then other living things ore also likely to be sufficiently protected." Radiation dose rates to aquatic biota were estimated for an aquatic pathway by using a human exposure of $1 \mathrm{mSv} \mathrm{a}^{-1}$. These estimates indicate that the ICRP statement is reasonable, at least within the generic scenario considered here. While a value of $1 \mathrm{mSv}$ for human exposure was used in. the scenario for estimating these doses, the prevailing radiation protection philosophy is to minimize human exposure well below the acceptable levels under the ALARA principle (As Low as Reasonably Achievable). Such a philosophy also minimizes the impact upon the natural population of aquatic organisms sharing the same environment with man. 


\section{References}

IAEA (1976). International Atomic Energy Agency. Effects of Ionizing Rodiation on Aquatic Organisms and Ecosystems, Technical Report Series No. 172 (International Atomic Energy Agency, Vienna).

IAEA (1979). International Atomic Energy Agency. Methodology for Assessing Impacts of Radioactivity on Aquatic Ecosystems, Technical Report Series No. 190 (International Atomic Energy Agency, Vienna).

ICRP (1977). International Commission on Radiation Protection. Radionuclide Releases into the Environment: Assessinent of Doses to Man. ICRP Publication 29 (Pergamon Press, New York).

NCRP (1990). National Council on Radiation Protection. Effects of Ionizing Radiation on Aquatic Organisms. NCRP Report in press.

Soldat, J. K., N. M. Robinson, and D. A. Baker, (1974). Models and Computer Codes for Evaluating Environmental Radiation Doses. BNWL-1754, Battelle Pacific Northwest Laboratory, Richland, Washington.

Trubey, D. K. and S. V. Kave, (1973). The EXREM III Computer Code for Estimating External Radiation Doses to Populations from Environmental Releases.

ORNL-TM-4322, Oak Ridge National Laboratory, Oak Ridge, Tennessee. 

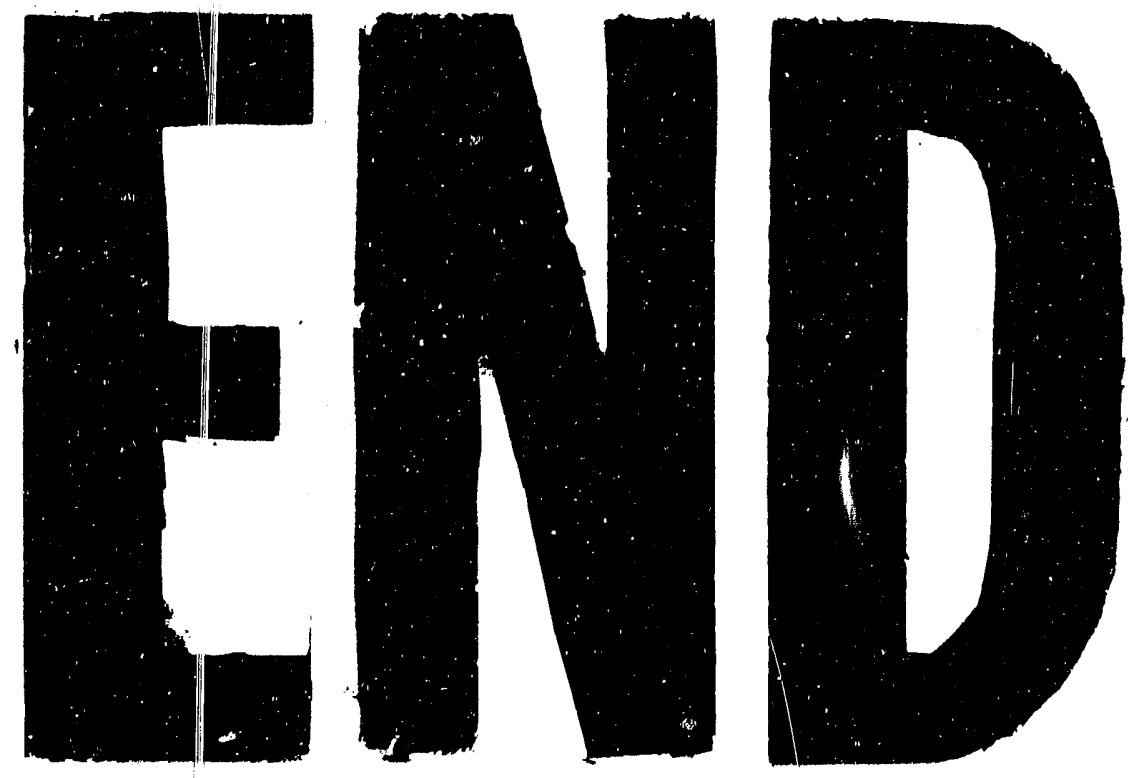

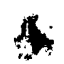
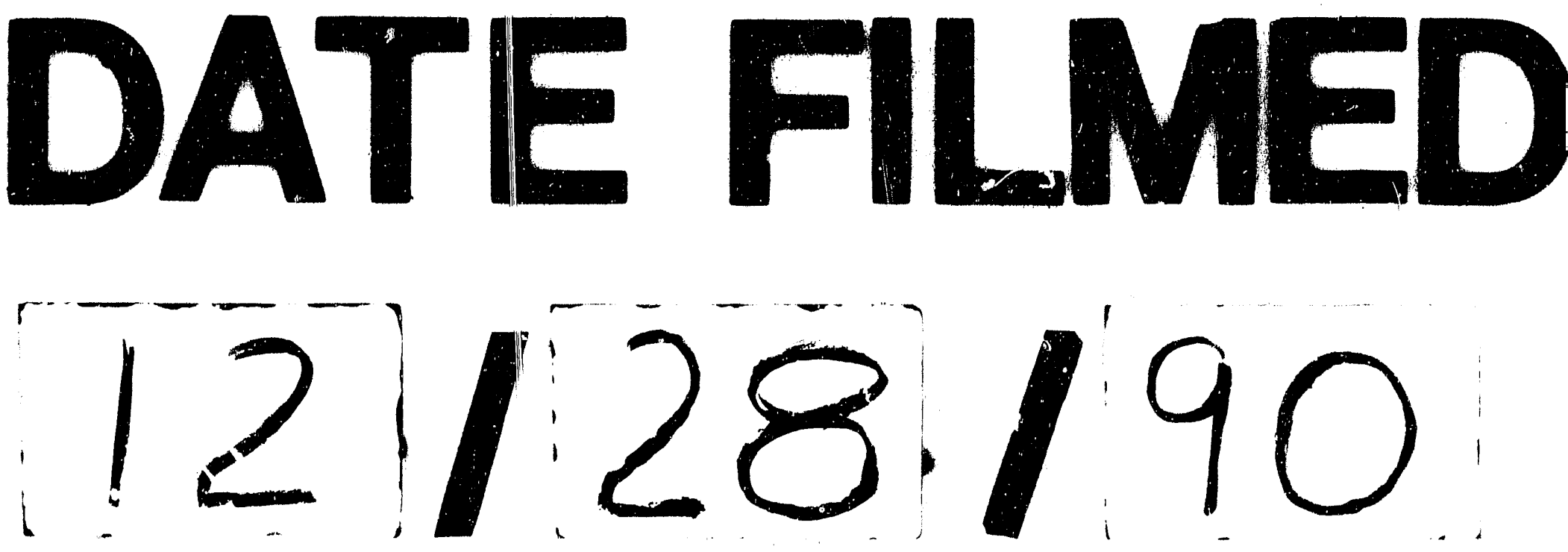
